\title{
PENGARUH HARGA DAN FASILITAS TERHADAP KEPUTUSAN BERKUNJUNG WISATAWAN DI OBJEK WISATA BUKIT GIBEON KECAMATAN AJIBATA KABUPATEN TOBA SAMOSIR
}

\author{
Helena Sirait \\ Alumni Jurusan Manajemen Fakultas Ekonomi Universitas Negeri Medan \\ Khafi Puddin \\ Dosen Jurusan Manajemen Fakultas Ekonomi Universitas Negeri Medan
}

\begin{abstract}
This study aims to determine and can explain the influence of price and facilities on Tourist Tourist Decision In Tourism Object Bukit Gibeon Ajibata District Toba Samosir. The population in this study is 143,769 tourists determined from the number of visitors Bukit Gibeon Tourism Object in the period of one year, and the sample used amounted to 100 visitors. Data analysis technique used is Multiple Linear Regression used questionnaires by distributing questionnaires to samples (respondents) and collecting them back for processing. Data analysis technique used is data quality test and classical assumption test. Hypothesis testing using multiple linear regression analysis, $T$ test, $F$ test, and $R^{2}$ test. Data analysis of each variable is obtained by multiple regression equation $Y=4,202+0,320 X 1+0,652 X 2+e$. Obtained $R^{2}$ equal to 0,349 which mean $X_{1}$ and $X_{2}$ explain influence to variable $Y$ equal to $34,9 \%$ while rest $65,1 \%$ explained variable outside company. The partial test resulted by each independent variable has an effect on the dependent variable with the research significance is smaller than 0.05, and the result of simultaneous-test calculation is 26,024 with $F$ table 3.09 which means $F$ count $>F$ table with level of significant $(\alpha)<0.05$, which means the accepted hypothesis that Price and Facilities together have a significant effect on Tourist Visits Decision. Thus it can be concluded that Price and Facilities have a positive effect on Tourist Visits Decision In Tourism Object Gibeon Bukit Ajibata District Toba Samosir.
\end{abstract}

\section{Keywords: Price, Facilities, and Tourist Visiting Decision}

\section{PENDAHULUAN}

Industri pariwisata saat ini dianggap sebagai industri yang paling pesat perkembangannya. Pariwisata memiliki peran strategis dalam perekonomian dan kesejahteraan masyarakat di berbagai daerah wisata. Objek wisata merupakan produk jasa yang ditawarkan oleh penyedia jasa agar konsumen datang untuk berwisata. Sekarang ini kunjungan wisata ke suatu daerah sudah menjadi bagian dari gaya hidup untuk memenuhi suatu keinginan atau kebutuhan masyarakat.

Saat ini industri pariwisata di Sumatera Utara sangat pesat perkembangannya, ini dapat dilihat dengan semakin banyaknya objek wisata yang bermunculan diberbagai daerah dengan daya tarik dan keunikan tersendiri salah satunya adalah Objek Wisata Bukit Gibeon yang terletak di Desa Parsaoran Kecamatan Ajibata, Kabupaten Toba Samosir. 
Pengelola bertindak dalam pengembangan objek wisata untuk menarik perhatian wisatawan dengan harapan agar konsumen datang berkunjung ke Objek Wisata Bukit Gibeon. Pertama hal yang harus diperhatikan dan dilakukan oleh pengelola objek wisata selain memiliki keunggulan/keunikan dalam produk jasa wisatanya yaitu fokus pada strategi pemasaran khususnya dalam penetapan harga. Karena harga merupakan satu-satunya unsur bauran pemasaran yang memberikan pemasukan atau pendapatan bagi perusahaan (Tjiptono, 2008: 151). Apabila pengelola salah dalam menetapkan harga maka akan mengganggu kegiatan operasional dan mengancam kelangsungan usaha. Penetapan harga berperan penting dalam keputusan berkunjung wisatawan, harga yang ditetapkan oleh pengelola hendaknya menyesuaikan dengan harapan wisatawan yang datang berkunjung.

Objek Wisata Bukit Gibeon menetapkan harga tiket masuk untuk pengunjung individual (perorangan), wisatawan dikenakan biaya sebesar Rp 10.000 per orang untuk dewasa, dan anak-anak dikenakan biaya $\mathrm{Rp}$ 5.000 per orang. Kemudian wisatawan dibebaskan untuk membawa bekal sendiri dan tidak diwajibkan membeli makanan maupun minuman di tempat wisata Bukit Gibeon, ini membuat wisatawan dapat menghemat biaya. Dalam menarik dan meningkatkan kunjungan wisatawan terutama bagi kalangan pelajar atau mahasiswa yang ingin berwisata tanpa harus mengeluarkan banyak biaya. Sesuai dengan hukum permintaan yaitu semakin rendah harga suatu produk, maka semakin banyak jumlah permintaan atas produk dan sebaliknya (Sadono Sukirno, 2011: 75).

Dalam upaya peningkatan laba dan mempertahankan kelangsungan usaha, pengelola Objek Wisata Bukit Gibeon menetapkan strategi yang tepat dengan memahami apa yang menjadi kebutuhan wisatawan dengan menawarkan harga yang terjangkau. Hal ini bertujuan untuk menarik wisatawan dalam melakukan keputusan berkunjung dan mencapai laba yang diinginkan pengelola.

Tabel 1. Data jumlah pengunjung objek Wisata Bukit Gibeon Desa Parsaoran Kec. Ajibata Kab. Toba Samosir Tahun 2016

\begin{tabular}{|l|c|c|c|}
\hline \multicolumn{1}{|c|}{ Bulan } & Dewasa & Anak-anak & $\begin{array}{c}\text { Jumlah } \\
\text { pengunjung }\end{array}$ \\
\hline Juni & 3.417 & 2.865 & 6.282 \\
\hline Juli & 5.038 & 4.786 & 9.824 \\
\hline Agustus & 4.637 & 3.978 & 8.615 \\
\hline September & 4.597 & 3.540 & 8.137 \\
\hline Oktober & 6.817 & 5.355 & 11.572 \\
\hline November & 10.187 & 8.694 & 18.881 \\
\hline Desember & 48.453 & 40.142 & 88.595 \\
\hline \multicolumn{1}{|c|}{ TOTAL } & $\mathbf{8 3 . 1 4 6}$ & $\mathbf{6 9 . 3 6 0}$ & $\mathbf{1 4 3 . 7 6 9}$ \\
\hline
\end{tabular}

Sumber : Objek Wisata Bukit Gibeon Kabupaten Toba Samosir (diolah 2017)

Berdasarkan Tabel 1. tersebut Gibeon tahun 2016 dimulai dari bulan jumlah kunjungan wisatawan Bukit Juni dikarenakan Objek Wisata Bukit 
Gibeon resmi dibuka pada bulan Juni 2016. Jika dilihat pada bulan Juni-Juli wisata Bukit Gibeon mengalami peningkatan jumlah wisatawan sebanyak 3.542 orang, peningkatan ini terjadi disebabkan pada bulan tersebut merupakan masa liburan sekolah dan hari besar yaitu hari raya Idul Fitri. Namun terjadi penurunan jumlah wisatawan di bulan AgustusSeptember dikarenakan pada bulan tersebut bukan masa liburan sekolah, kemudian pada bulan OktoberDesember wisata Bukit Gibeon terus mengalami peningkatan kunjungan wisatawan. Meskipun pada bulan Oktober dan November bukanlah masa liburan sekolah, dari pengamatan yang dilakukan peneliti mendapatkan informasi bahwa peningkatan jumlah kunjungan wisatawan ini terjadi karena adanya pembangunan kolam renang yang dilakukan oleh wisata Bukit Gibeon.

Fasilitas objek wisata yang menarik dan sesuai dengankeinginan yang sedang diminati, akan menjadi daya tarik bagi wisatawan untukberkunjung dan menikmati fasilitas tersebut, selain itu kebersihan, kelancaran danjaminan keamanan dari fasilitas juga menjadi nilai tambah untuk menarik konsumenuntuk berkunjung. Menurut Sulastyono (dalam Isti Faradisa, 2016) fasilitas adalah penyediaan perlengkapan-perlengkapan fisik untuk memberi kemudahan kepada konsumen untuk melaksanakan aktivitas-aktivitas sehingga kebutuhan konsumen dapat terpenuhi. Objek wisata Bukit Gibeon memiliki fasilitas yaitu kebun buah, penyewaan kuda, pondok, kantin, kamar mandi, air pancur, parkir yang luas, rumah retreat, bangunan gereja yang dinamai rumah doa segala bangsa, dan terdapat kolam renang yang airnya berasal dari air terjun alami yang didukung oleh lingkungan yang indah dan nyaman. Awalnya kolam renang di wisata Bukit Gibeon berjumlah 2 kolam renang yang terdiri dari 1 kolam dewasa dan 1 kolam untuk anak-anak. Setelah adanya pembangunan kolam renang menjadi 5 kolam renang yang terdiri dari 2 kolam berenang ukuran besar untuk dewasa dan 3 kolam berenang untuk anak-anak.

Ketika Objek Wisata Bukit Gibeon kedatangan wisatawan dalam jumlah besar terutama pada hari-hari tertentu seperti hari besar atau masa liburan sekolah, kepadatan jumlah pengunjung ini menyebabkan antrian yang panjang untuk masuk ke objek wisata bahkan wisatawan harus menunggu keluarnya kendaraan dari objek wisata agar dapat memarkirkan kendaraan. Wisatawan juga harus menempuh jarak yang jauh dari gapura (sebagai tanda persimpangan) jalan masuk menuju objek wisata. Kondisi sebagian besar jalan menuju objek wisata sudah beraspal dan dapat dilewati kendaraan, tetapi dalam menempuh perjalanan wisatawan dihadapkan kondisi jalan yang cukup menanjak, terjal, dan sempit. Meskipun demikian, Objek Wisata Bukit Gibeon tetap dikunjungi oleh banyak wisatawan dan mengalami peningkatan kunjungan yang signifikan pada bulan Desember 2016.

\section{KAJIAN PUSTAKA}

Harga

Pengertian harga dapat didefinisikan sebagai alat tukar, seperti yang dikemukakan oleh Kotler 
dan Armstrong (2012: 430) "harga yaitu jumlah semua nilai konsumen yang ditukarkan dalam rangka mendapatkan manfaat dan memiliki atau menggunakan suatu barang ataupun jasa".

Menurut Lupiyaodi (dalam Rizki Teguh, 2015:5) "harga adalah berbagai manfaat yang dimiliki oleh suatu produk jasa yang dibandingkan dengan berbagai biaya (pengorbanan) yang ditimbulkan dalam mengonsumsi jasa tersebut".

\section{Fasilitas}

Menurut Tjiptono (dalam Faradisa, 2016) fasilitas adalah penyediaan perlengkapanperlengkapan fisik untuk memberi kemudahan kepada konsumen untuk melaksanakan aktivitas-aktivitas sehingga kebutuhan konsumen dapat terpenuhi.

Fasilitas merupakan penampilan, kemampuan sarana prasarana, dan keadaan lingkungan sekitarnya dalam menunjukkan eksistensinya kepada eksternal yang meliputi fasilitas fisik (gedung), perlengkapan dan peralatan (Lupioadi, 2008: 148). Sedangkan menurut Sulastiyono (dalam Nicklouse, 2015 : 1072) mengatakan bahwa fasilitas adalah penyediaan perlengkapan-perlengkapan fisik untuk memberikan kemudahan kepada para tamu dalam melaksanakan aktivitas-aktivitasnya atau kegiatan-kegiatannya, sehingga kebutuhan-kebutuhan tamu dapat terpenuhi.

\section{Keputusan Berkunjung Wisatawan}

Keputusan berkunjung wisatawan merujuk pada konsep keputusan pembelian konsumen yang diadaptasi menjadi keputusan berkunjung wisatawan, seperti penelitian yang dilakukan oleh Jalilvand dan Samiei (dalam Fitri, dkk 2015: 3) yang menyamakan teori keputusan berkunjung wisatawan sama dengan keputusan pembelian konsumen.

Menurut Tjiptono (2008: 21) keputusan pembelian adalah sebuah proses dimana konsumen mengenal masalahnya, mencari informasi mengenai produk atau merek tertentu dan mengevaluasi seberapa baik masing-masing alternatif tersebut dapat memecahkan masalahnya, yang kemudian mengarah kepada keputusan pembelian. Keputusan pembelian adalah tahap di mana pembeli telah menentukan pilihannya dan melakukan pembelian produk, serta mengkonsumsinya (Suharno, 2010: 96).

Menurut Swastha dan Handoko (2012: 15), keputusan pembelian adalah sebuah pendekatan penyelesaian masalah pada kegiatan manusia untuk membeli suatu barang atau jasa dalam memenuhi keinginan dan kebutuhannya yang terdiri dari pengenalan kebutuhan dan keinginan, pencarian informasi, evaluasi terhadap alternatif pembelian, keputusan pembelian, dan tingkah laku setelah pembelian.

\section{METODE PENELITIAN}

Penelitian ini dilakukan di Objek Wisata Bukit Gibeon Desa Parsaoran Sibisa Kecamatan Ajibata Kabupaten Toba Samosir. Populasi adalah wilayah generalisasi yang terdiri atas objek atau subyek yang 
mempunyai kualitas dan karakteristik tertentu yang ditetapkan oleh peneliti (Sugiyono, 2013: 61). Berdasarkan data jumlah wisatawan Bukit Gibeon Kecamatan Ajibata Kabupaten Toba Samosir, jumlah populasi adalah 143.769 wisatawan. Sampel adalah bagian dari jumlah dan karakteristik yang dimiliki oleh populasi tersebut (Sugiyono, 2013: 62). jumlah responden yang akan dijadikan sampel dalam penelitian ini adalah 100 wisatawan. Teknik pengumpulan datanya dengan menggunakan metode purposive sampling, yaitu teknik pengambilan sampel dengan pertimbangan karakter dan ciri-ciri yang ditentukan terlebih dahulu untuk membatasi sampel (Sugiyono, 2013: 68). Kriteria sampel adalah wisatawan Bukit Gibeon adalah wisatawan yang membeli tiket masuk dewasa.

Teknik analisis data yang digunakan dalam penelitian ini adalah analisis regresi berganda dan juga menggunakan uji asumsi klasik yaitu uji normalitas, uji multikoleniaritas, serta uji heteroskedastisitas. Untuk menguji kebenaran hipotesis digunakan uji $\mathrm{F}$ yaitu untuk menguji keberartian/signifikansi regresi secara keseluruhan, dan uji t untuk pengujian regresi secara terpisah atau parsial antar masing-masing variabel independen terhadap variabel dependen.

\section{HASIL PENELITIAN DAN PEMBAHASAN \\ Analisis Regresi Berganda}

Hasil dari pengolahan data analisis regresi berganda adalah sebagai berikut :

$$
\begin{aligned}
& \mathrm{Y}=\mathbf{4 , 2 0 2}+\mathbf{0 , 3 2 0} \mathrm{X}_{\mathbf{1}}+\mathbf{0 , 6 5 2} \mathrm{X}_{\mathbf{2}}+\mathrm{e} \\
& \text { 1. Konstanta sebesar 4,202 } \\
& \text { menyatakan bahwa jika tidak ada }
\end{aligned}
$$

variabel $X$, yaitu Harga, dan Fasilitasmaka Keputusan Berkunjung Wisatawan adalah sebesar 4,202 dengan asumsi faktor lain konstan.

2. Koefisien $X_{1}$ sebesar 0,320 menyatakan bahwa setiap terjadi peningkatan Harga akan mempengaruhi Keputusan Berkunjung Wisatawan sebesar 0,320 dengan asumsi faktor lain konstan.

3. Koefisien $\mathrm{X}_{2}$ sebesar 0,652 menyatakan bahwa setiap terjadi peningkatan Fasilitas akan mempengaruhi Keputusan Berkunjung Wisatawan sebesar 0,652 dengan asumsi faktor lain konstan.

\section{Uji Hipotesis}

Uji t (Parsial)

Dari hasil SPSS maka dapat dijelaskan bahwa $t_{\text {tabel }}$ dapat dilihat pada tabel statistik pada tingkat signifikansi 0,05 dengan $\mathrm{df}=$ variabel$1(3-1)=2$ maka df( n-k-1) atau 100$2-1=97$.

1. Nilai $t_{\text {hitung }}$ variabel Harga 3,288 $>$ dari $t_{\text {tabel }}$ yaitu 1,660 dan nilai signifikan $0,001<0,05$. Hal ini berarti hipotesis diterima yaitu : Harga secara parsial berpengaruh positif dan signifikan terhadap Keputusan Berkunjung Wisatawan pada Objek Wisata Bukit Gibeon.

2. Nilai $t_{\text {hitung }}$ variabel Fasilitas $6,160>$ dari $t_{\text {tabel }}$ yaitu 1,660 dan nilai signifikan $0.000<0,05$. Hal ini berarti hipotesis diterima yaitu Fasilitas secara parsial berpengaruh positif dan signifikan terhadap Keputusan Berkunjung Wisatawan pada Objek Wisata Bukit Gibeon. 


\section{Uji F (Simultan)}

Hasil SPSS diperoleh bahwa nilai Fhitung $=26,024$ dengan tingkat signifikansi $0,00<0,05$. Ftabel dapat dilihat pada tabel statistik pada tingkat signifikansi 0,05 dengan $\mathrm{df}=$ variabel-1 (3-1) $=2$, maka $\mathrm{df}(\mathrm{n}-\mathrm{k}-1)$ atau $100-2-1=97$. Setelah mengetahui Fhitung, maka akan di bandingkan dengan Ftabel dengan taraf kesalahan $5 \%$ adalah $=3,09$, maka Fhitung $=26,024>$ Ftable $(3,09)$. Dengan demikian, dapat ditarik kesimpulan koefisien arah regresi berganda pada taraf signifikan 0,05 yang artinya Harga dan Fasilitas secara bersama-sama berpengaruh positif dan signifikan terhadap Keputusan Berkunjung Wisatawan pada Objek Wisata Bukit Gibeon.

\section{Uji Koefisien Determinasi $\left(\mathbf{R}^{2}\right)$}

Untuk mengetahui seberapa besar persentase pengaruh variabel independent terhadap variabel dependent atau untuk melihat seberapa besar variabel independent dapat menjelaskan pengaruhnya terhadap variabel dependent, maka dilakukan pengujian koefisien determinasi $\left(\mathrm{R}^{2}\right)$. Dari output SPSS dapat dilihat bahwa koefisien determinan $\left(\mathrm{R}^{2}\right)$ adalah sebesar 0,349 . Nilai ini menunjukan bahwa variabel Keputusan Berkunjung Wisatawan (Y) dipengaruhi oleh variabel Harga $\left(\mathrm{X}_{1}\right)$ dan Fasilitas $\left(\mathrm{X}_{2}\right)$ secara bersama-sama sebesar 34,9\% dan sisanya $65,1 \%$ dipengaruhi oleh variabel lain yang tidak dibahas dalam penelitian ini.

\section{PENUTUP}

Berdasarkan hasil penelitian dan pembahasan, maka dapat diambil kesimpulan sebagai berikut :
1. Pengaruh Harga terhadap Keputusan Berkunjung Wisatawan di Objek Wisata Bukit Gibeon, dapat disimpulkan bahwa secara parsial variabel Harga berpengaruh positif terhadap Keputusan Berkunjung Wisatawan di Objek Wisata Bukit Gibeon. Hal ini mendukung hipotesis yang menyatakan bahwa Harga berpengaruh terhadap Keputusan Berkunjung Wisatawan di Objek Wisata Bukit Gibeon.

2. Pengaruh Fasilitas terhadap Keputusan Berkunjung Wisatawan di Objek Wisata Bukit Gibeon, dapat disimpulkan bahwa secara parsial variabel Fasilitas berpengaruh positif terhadap Keputusan Berkunjung Wisatawan di Objek Wisata Bukit Gibeon. Hal ini mendukung hipotesis yang menyatakan bahwa Fasilitas berpengaruh terhadap Keputusan Berkunjung Wisatawan di Objek Wisata Bukit Gibeon.

3. Pengaruh Harga dan Fasilitas terhadap Keputusan Berkunjung Wisatawan di Objek Wisata Bukit Gibeon, dapat disimpulkan bahwa secara simultan variabel Harga dan Fasilitas berpengaruh positif dan signifikan terhadap Keputusan Berkunjung Wisatawan di Objek Wisata Bukit Gibeon. Hal ini mendukung hipotesis yang menyatakan bahwa Harga dan 
Fasilitas berpengaruh secara simultan terhadap Keputusan Berkunjung Wisatawan di Objek Wisata Bukit Gibeon.

\section{DAFTAR PUSTAKA}

Alma, Buchari.

2001 Kewirausahaan. Bandung : Bima Cipta.

Desembrinita, Eva dan Ruslin. 2016. Pengaruh Pelayanan, Fasilitas, Dan Harga Terhadap Keputusan Pelanggan Untuk Menggunakan Jasa Hotel Oval Surabaya. Vol.16 No.2.

Faradisa, Isti dkk. 2016. Analisis Pengaruh Variasi Produk, Fasilitas, Dan Kualitas Pelayanan Terhadap Minat Beli Ulang Konsumen Pada Indonesian Coffeeshop Semarang (Icos Café). Vol.2 No.2.

Ferdinand, Agusty. 2006. Metode Penelitian Manajemen : Pedoman Penelitian untuk Penulisan Skripsi, Tesis dan Disertasi Ilmu Manajemen. Semarang : Badan Penerbit Universitas Diponegoro.

Fitri, dkk. 2015. Pengaruh Word Of Mouth Terhadap Minat Berkunjung Serta Dampaknya Pada Keputusan Berkunjung (Survei pada Pengunjung Tempat Wisata "Jawa Timur Park 2" Kota Batu). Vol. 24 No. 1.

Kotler, Amstrong. 2012. PrinsipPrinsip Pemasaran. Jilid 1 Edisi 13. Jakarta: PT Gelora Aksara Pratama.

Kotler, Keller. 2012. Manajemen Pemasaran. Jilid 2 Edisi 13. Jakarta: Erlangga.
Lalu, Sumayang. 2003. Dasar-dasar Manajemen Produksi dan Operasi. Jakarta: Salemba Empat.

Lupioadi, Rambat, dan Hamdani,A. 2008. Manajemen Pemasaran Jasa. Jakarta: Salemba Empat.

Margaretith, Popy dan Altje Tumbel. 2016. Pelayanan, Keamanan Dan Daya Tarik Mempengaruhi Minat Wisatawan Yang Berkunjung Ke Objek Wisata Alam Gunung Mahawu, Tomohon. Vol.16, No.01.

Nicklouse, dkk. 2015. Pengaruh Harga, Lokasi, Dan Fasilitas Terhadap Keputusan Menggunakan Jasa Taman Wisata Toar Lumimuut (Taman Eman) Sonder. Vol.3 No.1.

Setiadi, Nugroho J. 2003. Konsep dan Impilikasi Untuk Strategi Penelitian Konsumen. Bogor : Kencana

Simamora, Bilson. 2003. Panduan Riset Perilaku Konsumen. Jakarta: $\quad$ PT Gramedia Pustaka Utama.

Sofyan, Indra, dkk. 2013. Pengaruh Fasilitas dan Kualitas Pelayanan Terhadap Loyalitas, Melalui Kepuasan Konsumen Sebagai Variabel Intervening pada Star Clean Car Wash Semarang. Vol. 21 No. 2.

Sugiyono. 2013. Metode Penelitian Manajemen. Bandung : Alfabeta.

Suharno. 2010. Marketing In Practice. Yogyakarta : Graha Ilmu. 
JURNAL PLANS

Penelitian Ilmu Manajemen \& Bisnis

ISSN: $1978-7057$

E-ISSN: 2527-306X

Sukirno, Sadono. 2011. Mikro

Swastha, B. dan Irawan. 2008.

Ekonomi Teori Pengantar Edisi Ketiga. Jakarta: Raja Grafindo Persada.

Manajemen

Pemasaran

Modern. Yogyakarta:

Liberty.

Suwantoro, Gamal. 2004. DasarDasar

Pariwisata.

Yogyakarta : Andi

Swastha, Basu dan T. Hani Handoko.

2012.

Manajemen

Pemasaran : Analisis

Perilaku Konsumen.

Yogyakarta : BPFE.

Teguh, Rizki, dkk. 2015. Pengaruh Fasilitas Wisata Dan Harga Terhadap Kepuasan Konsumen (Studi Pada Museum Satwa).Vol. 25 No 1.

Tjiptono, Fandy. 2008. Pemasaran Jasa. Edisi Ketiga. Malang : Penerbit Bayumedia. 